\title{
A Novel Approach towards Green Extraction for Glycyrrhitinic Acid by lonic Liquid Based Microwave Assisted Extraction and Optimization through Response Surface Methodology
}

\author{
Meenu Bhan ${ }^{1}$, Saurabh Satija ${ }^{2}$, Chanchal Garg ${ }^{1}$, Harish Dureja ${ }^{1}$, Munish Garg ${ }^{1 *}$
}

\section{Meenu Bhan', Saurabh Satija², Chanchal Garg ${ }^{1}$, Harish Dureja', Munish Garg ${ }^{1 *}$ 'Department of Pharmaceutical Sciences, Maharshi Dayanand University, Rohtak, Haryana, INDIA. \\ ${ }^{2}$ Assistant Professor School of Pharma- ceutical Sciences Lovely Professional University, Punjab, INDIA.}

\section{Correspondence}

Dr. Munish Garg

Department of Pharmaceutical Sciences, Maharshi Dayanand University, Haryana-124001, INDIA.

Phone no: +911262-393222

E-mail: mgarg2006@gmail.com

History

- Submission Date: 10-06-2017

- Review completed: 27-07-2017;

- Accepted Date: 31-08-2017

DOI : 10.5530/pj.2017.6.136

Article Available online

http://www.phcogj.com/v9/i6

\section{Copyright}

(C) 2017 Phcog.Net. This is an openaccess article distributed under the terms of the Creative Commons Attribution 4.0 International license.

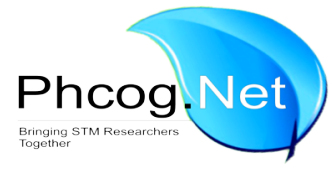

\begin{abstract}
Background: Extraction process plays an important role in extraction of herbal bioactive components. Ionic liquid based microwave assisted extraction (IL-MAE) has the potential to yield maximum analytes from the crude drugs in shorter time period with less solvent consumption and greater efficiency. Objective: The present study aimed to develop new protocol of Ionic Liquids based Microwave-assisted Extraction (ILs-MAE) of glycyrrhetinic acid from licorice; optimization of the protocol through RSM and comparison of IL-MAE with conventional extraction techniques like maceration and soxhlation by HPTLC. Materials and Methods: A novel ionic liquid-based microwave assisted extraction (IL-MAE) method was carried out for glycyrrhitinic acid from Glycyrrhiza glabra using ionic liquid, 1-butyl-3-methyl-imidazolium chloride ([bmim] Cl) and optimized by response surface methodology. The variable microwaveassisted extraction parameters selected were concentration of [bmim] Cl, extraction time and microwave power while solid-liquid ratio and extraction temperature were kept constant. Response surface methodology was applied for developing, improving and optimizing the whole process and comparison of IL-MAE with maceration and soxhlation by HPTLC. Results: The yield of glycyrrhitinic acid was found to be $0.48 \% \mathrm{w} / \mathrm{w}$ in maceration in 7 days, $0.76 \%$ in soxhlation in $3 \mathrm{~h}$ and $2.54 \% \mathrm{w} / \mathrm{w}$ in IL-MAE in $4 \mathrm{~min}$. Conclusion: IL- MAE of glycyrrhitinic acid from Glycyrrhiza glabra was proved to be better in respect of extraction efficiency, time and quantity of solvent used. Meanwhile, there was great reduction in the environmental pollution by using the green solvents/ ionic liquids (ILs), which is a great benefit to all.

Key words: Novel, [bmim]Cl, Glycyrrhiza glabra, Glycyrrhitinic acid, Microwave assisted extraction, Response surface methodology.
\end{abstract}

\section{INTRODUCTION}

Green extraction is the need of today's environment for the safety purpose as well as for the advancement in the conventional methods of extraction. Ionic liquids plays an important role in fulfilling this criterion. The ionic liquid (IL) are a class of liquids that are entirely composed of ions. ${ }^{1}$ ILs are the innovative solvents having provocating properties, which are captivating a number of scientists. As a result of of some of their uniquely fascinating properties, such as high thermal stability, negligible vapour pressure, highly dissolving ability of organic, inorganic and polymeric compounds. ${ }^{2}$ They also gain popularity as alternative 'green solvents' to volatile organic solvents (VOCs) for separation processes, electrochemical and synthetic reactions. 'ILs' are now commonly termed as low-melting salts having melting-point typically less than $100^{\circ} \mathrm{C}$ obtained from the combination of large organic cations with variable anions. ${ }^{3}$ Now, ILs are most frequently used as more than a Alternative "green" solvent. They diverge from molecular solvents by having a particular ionic character and its structural organisation which leads to specific effect. They are tuneable, Multipurpose materials. ${ }^{4}$

Glycyrrhiza glabra Linn. belonging to family Fabaceae generally known as Mulaithi or Liquorice is a smal perennial herb native to the Mediterranean region, central and southwest Asia. It is cultivated in Italy, Russia, France, UK, USA, Germany, Spain, China and Northern India. ${ }^{5}$ Traditionally, Glycyrrhiza species have been claimed for the efficacy of diuretic, choleretic, a variety of pathological conditions, coughs, colds and painful swellings and insecticide also. ${ }^{6}$ It is widely used as anti-tussive and expectorant, antioxidant, skin lightening and skin tightening, anti-bacterial, anti-fungal, anti-viral, anti-malarial, anti hyperglycemic, immunostimulatory, memory enhancing, anti-inflammatory hepatoprotective, anticoagulant and hair growth stimulatory effects. ${ }^{\text {? }}$

The primary active constituent of Glycyrrhiza is glycyrrhizin (glycyrrhizic acid; glycyrrhizinate) constitutes $10-25 \%$. It is a type of saponin com-

Cite this article: Bhan M, Satija S, Garg C, Dureja H, Garg M. A Novel Approach towards Green Extraction for Glycyrrhitinic Acid by lonic Liquid Based Microwave Assisted Extraction and Optimization through Response Surface Methodology. Pharmacog J. 2017;9(6):866-72. 
pound composed of triterpenoid aglycone, glycyrrhetic acid (glycyrrhetinic acid; enoxolone) conjoined to a disaccharide of glucuronic acid. Glycyrrhetic acid and glycyrrhizin occurs in the $18 \alpha$ and $18 \beta$ stereoisomer forms. ${ }^{8}$

Glycyrrhetinic acid (GA) ia s very potent constituent of Glycyrrhiza as revealed from the previous studies. Glycyrrhetinic acid (GA) is more potent than glycyrrhizin (GL) proved from preincubated fresh rat hepatocyte suspensions with GA and GL. The decreased glycochenodeoxycholic acid (GCDC)-dependent reactive oxygen species generation, specified that GA was more potent than GL. Additionally, GA and GL had antagonistic effects toward GCDC-induced cytotoxicity; GL enhanced apoptosis whereas GA prevented both necrosis and apoptosis. ${ }^{9}$ GA effect on the subcutaneous fat thickness was performed through topically applied cream containing GA, results in reduction of unwanted local fat accumulation. It was found to be due to the blockage of $11 \beta$-hydroxysteroid dehydrogenase type 1 at the level of fat cells. ${ }^{10} \mathrm{~A}$ comparison between glycyrrhizin (18 $3-\mathrm{GL})$ and its aglycone, glycyrrhetinic acid (18 $\beta-G A)$ for antihepatotoxic activity, was carried out using in vivo and in vitro assay by means of oral and intraperitoneal administration and also through $\mathrm{CCl}_{4}$-induced cytotoxicity in primary cultured rat hepatocytes. The results showed that $18 \alpha, \beta-G A$ was a more potent antihepatotoxic agent than $18 \alpha, \beta-G L{ }^{11}$

Ionic liquid-based ultrasonic-assisted extraction (ILUAE) method had been performed for the extraction of liquiritin (LQ), isoliquiritigenin (IQ), and glycyrrhizic acid (GA) from liquorice. Ionic liquids with variable anions and cations were investigated but $0.5 \mathrm{M} 1$ - butyl-3-methylimidazolium bromide solution was selected as solvent. This method exhibited higher efficiency compared with conventional solvent extraction, which revealed that ILUAE as an efficient, simple and environmental friendly technique. The target analytes shows no degradation as evidenced by the stability studies performed by standard IQ, LQ and GA. ${ }^{12}$ Glabridin was extracted from licorice with 1-alkyl-3-methylimidazolium IL series having variable anions and alkyl chain lengths of cations. The results showed that IL anions have a convincing effect on the extraction efficiency of glabridin, while the alkyl chain length of imidazolium cations have comparative negligible effect on the extraction efficiency of glabridin. ${ }^{13}$ Optimization alludes to improve the performance of a system, a product or a process, in order to attain the maximal benefit from it. It obtains the best optimum values of a dependent variable by varying certain independent variables. ${ }^{14}$ Response surface methodology (RSM) is a mathematical and statistical technique for framing models, identfying the effects of different variables, and achieving the process variables value which gives desirable values of the response. In response surface design there is a set of design of experiments (DOE) that helps for the better understanding and optimization of the response. RSM is used to refine models in order to determines important factors using factorial designs. ${ }^{15}$

Novel approaches reported the use of ionic liquids as alternative solvents for extraction purpose with the aim in proving ionic liquids as environment friendly solvents representing them as green solvents. There is no report of extracting glycyrrhitinic acid by Glycyrrhiza glabra through ILMAE.

\section{MATERIALS AND METHODS}

\section{Instrumentation}

Microwave assisted extraction experiments were performed with an UWave-1000 Microwave -Ultraviolet-Ultrasonic Synthesis Extraction Reactor (Sineo Microwave Chemistry Technology Co., Ltd, China) with a max. power of $1000 \mathrm{~W}$, and it is a mono-mode with a temperature versus time and power versus time control. For the temperature moni- toring there was a platinum probe inside the microwave cavity. The concentration of glycyrrhitinic acid in the extracts were detected by a Camag HPTLC system equipped with Camag Linomat 5 automatic sampler, Camag TLC Plate Heater III for drying the HPTLC plate (TLC Silica gel $60 \mathrm{~F}_{254} 1.05554 .0007$ of Merck, Germany), Camag developing chamber for developing the plates, Camag TLC Visualizer for visualizing and Camag TLC Scanner 3 for scanning the developed plates. The samples were injected by Camag Linomat syringe 695.0014 Hamilton Bonaduz, Schweiz.

\section{MATERIALS / REAGENTS}

Glycyrrhiza glabra dried stolons were collected from the local market of Rohtak and authenticated by Dr. Surinder Singh, Department of Botany of the University. Voucher specimen no. VS/Phcog/2017/182 was kept in the department for future reference. Standard marker compound of glycyrrhitinic acid was purchased from Yucca Laboratories, Mumbai. Ionic liquid, 1-butyl-3-methyl-imidazolium chloride was purchased from Sigma Aldrich. Toluene, ethyl acetate and glacial acetic acid were purchased from $\mathrm{CDH}$, India (AR grade). Deionized water was used throughout the process. For HPTLC, all the solutions were strained by $0.45 \mu \mathrm{m}$ nylon membrane.

\section{METHODS}

\section{Development of calibration curve of glycyrrhitinic acid}

To determine the concentration of glycyrrhitinic acid in Glycyrrhiza glabra, standard glycyrrhitinic acid was used to plot the curve by HPTLC. Stock solution of $100 \mu \mathrm{g} / \mathrm{ml}$ concentration of glycyrrhitinic acid was used for making standard curve. Then standard glycyrrhitinic acid was mixed with methanol for making varrying concentration (200-1600 ng) was applied on pre-coated silica gel HPTLC plate and run the plate to a distance of $80 \%$ in the solvent system (toluene: ethyl acetate: glacial acetic acid :: 12.5: 7.5: 0.5$)$ at room temperature $\left(25 \pm 2^{\circ} \mathrm{C}\right) .{ }^{16}$ The developed plate was dried on TLC plate heater and scanned at $254 \mathrm{~nm}$. Peak area vs. concentration was used for plotting calibration curve.

\section{Ionic liquid-based microwave assisted extraction} (IL-MAE)

$1 \mathrm{~g}$ of drug mixed with $10 \mathrm{~mL}$ IL- $[\mathrm{bmim}(\mathrm{Cl})]$ solution and extracted through microwave assisted extraction technique. IL solutions were made by dissolving a required quantity of $[\mathrm{bmim}(\mathrm{Cl})]$ in deionized water for making the concentration range from 1.0 to $3.0 \mathrm{~mol} / \mathrm{L}$. The optimum extraction conditions were consistently studied. The obtained suspensions after MAE, were cooled to room temperature and filtered. Filterate was diluted to $10 \mathrm{~mL}$ with deionized water and then filtered through $0.45 \mu \mathrm{m}$ nylon filter for the consiquent HPTLC analysis. ${ }^{17}$

\section{Conventional reference extraction methods}

Maceration and soxhlation were the conventional extraction methods employed. In maceration method, inside a closed vessel $10 \mathrm{~g}$ of coarsely powdered Glycyrrhiza glabra, was placed, added $100 \mathrm{~mL}$ methanol and allowed the extraction for 7 days with occasional stirring at room temperature. It was then filtered and calculated the percentage yield of extract. In soxhlation method, soxhlet apparatus was used where inside a thimble holder $20 \mathrm{~g}$ powdered Glycyrrhiza glabra was placed, added $500 \mathrm{ml}$ of methanol in distillation flask and extracted for $3 \mathrm{~h}$. The extract was filtered, evaporated on a water bath to give dried extract and calculated the percentage yield. 


\section{HPTLC analysis}

Before HPTLC analysis, all the standard solutions of glycyrrhitinic acid and extracts were filtered through $0.45 \mu \mathrm{m}$ microporous membrane. The solvent chamber was saturated with solvent system (toluene: ethyl acetate: glacial acetic acid :12.5: 7.5: 0.5$)$ at room temperature $\left(25 \pm 2^{\circ} \mathrm{C}\right)$. Sample was applied on plate and run upto $80 \%$ in the mobile phase, then allowed to dry on TLC plate heater. Then plates were scanned for the separated bands on 254 and $366 \mathrm{~nm}$ wavelength. At $254 \mathrm{~nm}$ maximum absorbance was found. Peak area was used for the quantification of glycyrrhitinic acid in extracts using standard calibration curve equation.

\section{Experimental design and statistical analysis}

RSM was utilized for experimental design, model building and data analysis with software Design Expert (v.8.0.7.1). Central composite design was employed with three variables and two levels to find out the response pattern and then to establish a model. All variables were taken at a central coded value zero. According to the results of single factor experiments, three independent variables with two levels for each were concentration of $[\mathrm{bmim}] \mathrm{Cl}\left(\mathrm{X}_{1}\right)$, microwave power $\left(\mathrm{X}_{2}\right)$, extraction time $\left(\mathrm{X}_{3}\right)$, while the dependent variable was the yield of glycyrrhitinic acid.

Table 1: Experimental factors level used in central composite design

\begin{tabular}{|c|c|c|c|c|c|}
\hline Factors & Unit & Notation & $\begin{array}{l}\text { Range and } \\
\text { levels (Xi) }\end{array}$ & & \\
\hline $\begin{array}{l}\text { Concentration } \\
\text { of [bmim }] \mathrm{Cl}\end{array}$ & $\mathrm{mol} \mathrm{L}^{-1}$ & $\mathrm{X}_{1}$ & $-1(1)$ & $0(2)$ & $1(3)$ \\
\hline $\begin{array}{c}\text { Microwave } \\
\text { power }\end{array}$ & W & $\mathrm{X}_{2}$ & $-1(500)$ & $0(600)$ & $1(700)$ \\
\hline $\begin{array}{l}\text { Extraction } \\
\text { time }\end{array}$ & $\min$ & $\mathrm{X}_{3}$ & $-1(2)$ & $0(4)$ & $1(6)$ \\
\hline
\end{tabular}

The range of the selective process variables with their units and notation are shown in Table 1. Randomized experiments were carried out to find out the maximum response of unexplained variability in the attained responses, due to extraneous factors.

Twenty experiments were carried out according to CCD design as shown in Table 2. The number of experiments are designed according to the equation $2^{\mathrm{k}}+2 \mathrm{k}+6$, where $\mathrm{k}$ represents the number of factors to be studied. This design comprised of a two- level full factorial design (coded \pm 1 ), superimposed by centre points (coded 0 ) and star points (coded $\pm \alpha$ ). The axial experiments or 'star points' are located at a distance $\alpha$ from the centre, allows rotatability. Analysis of variance (ANOVA) was used for the developed model and statistical significance of the regression coefficients were tested. $\mathrm{p}$ - Values of less than 0.05 were considered to be statistically significant. The response surface $3 \mathrm{D}$ plots and the contour plots were analysed for knowing the interactions between various independent variables and their resultant effect on the response.

\section{RESULTS AND DISCUSSION}

\section{Impact of [bmim]Cl concentration on the yield of glycyrrhitinic acid}

The ionic liquid concentration plays an important role in extracting the analyte from the drugs. For the estimation of optimum ILMAE concentration of target compounds, extraction was carried out using $1.0 \mathrm{~g}$ sample, different $[\mathrm{bmim}] \mathrm{Cl}$ concentrations $1.0,2.0,3.0,4.0,5.0$ $\mathrm{mol} / \mathrm{L}$ respectively, while other extraction parameters were: extraction temperature $70{ }^{\circ} \mathrm{C}$, extraction time $6 \mathrm{~min}$, microwave power $600 \mathrm{~W}$ and solid-liquid ratio 1:10. Figure 1 indicated that the concentration of glycyrrhitinic acid increased with the increase of the concentration of [bmim $] \mathrm{Cl}$ and attain the higher yield value about $2.54 \% \mathrm{w} / \mathrm{w}$ when the concentration of $[\mathrm{bmim}] \mathrm{Cl}$ is higher than $3.0 \mathrm{~mol} / \mathrm{L}$, indicating that the concentration of glycyrrhitinic acid increasing slowly. But when the

Table 2: Test design and result of response surface method analysis $(n=3)$

\begin{tabular}{|c|c|c|c|c|}
\hline $\begin{array}{c}\text { Experiment/ } \\
\text { Run }\end{array}$ & $\begin{array}{c}\mathrm{X}_{1} \\
\text { (Concentration of }[\mathrm{bmim}] \mathrm{Cl} \text { ) }\end{array}$ & $\begin{array}{c}\mathrm{X}_{2} \\
\text { (Microwave power) }\end{array}$ & $\begin{array}{c}\mathrm{X}_{3} \\
\text { (Extraction time) }\end{array}$ & $\begin{array}{c}\mathrm{Y} \\
\text { (Yield) }\end{array}$ \\
\hline 1 & -1 & -1 & -1 & 0.97 \\
\hline 2 & 1 & -1 & -1 & 1.05 \\
\hline 3 & -1 & 1 & -1 & 1.10 \\
\hline 4 & 1 & 1 & -1 & 1.95 \\
\hline 5 & -1 & -1 & 1 & 1.05 \\
\hline 6 & 1 & -1 & 1 & 1.59 \\
\hline 7 & -1 & 1 & 1 & 0.97 \\
\hline 8 & 1 & 1 & 1 & 1.93 \\
\hline 9 & -1.68 & 0 & 0 & 0.87 \\
\hline 10 & 1.68 & 0 & 0 & 2.54 \\
\hline 11 & 0 & -1.68 & 0 & 2.31 \\
\hline 12 & 0 & 1.68 & 0 & 2.4 \\
\hline 13 & 0 & 0 & -1.68 & 0.57 \\
\hline 14 & 0 & 0 & 1.68 & 2.05 \\
\hline 15 & 0 & 0 & 0 & 2.19 \\
\hline 16 & 0 & 0 & 0 & 2.39 \\
\hline 17 & 0 & 0 & 0 & 2.15 \\
\hline 18 & 0 & 0 & 0 & 1.89 \\
\hline 19 & 0 & 0 & 0 & 1.92 \\
\hline 20 & 0 & 0 & 0 & 1.79 \\
\hline
\end{tabular}




\begin{tabular}{cccccc} 
Table 3: Variance analysis of regression equations \\
\hline & Degree of freedom & Sum of squares & Mean square & F-value & F-significance \\
\hline Regression & 9 & 5.48 & 0.61 & 3.87 & $0.0232^{\star}$ \\
Residual & 10 & 1.58 & 0.16 & - & - \\
Total & 19 & 7.06 & - & - & - \\
\hline
\end{tabular}

$\mathrm{P}^{*}<0.0232 \%$

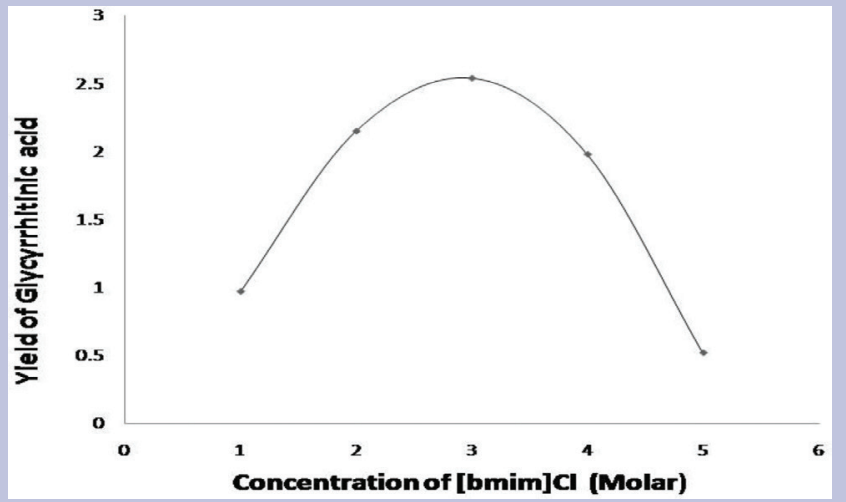

Figure 1: Impact of [bmim] Cl concentration on the yield of glycyrrhitinic acid.

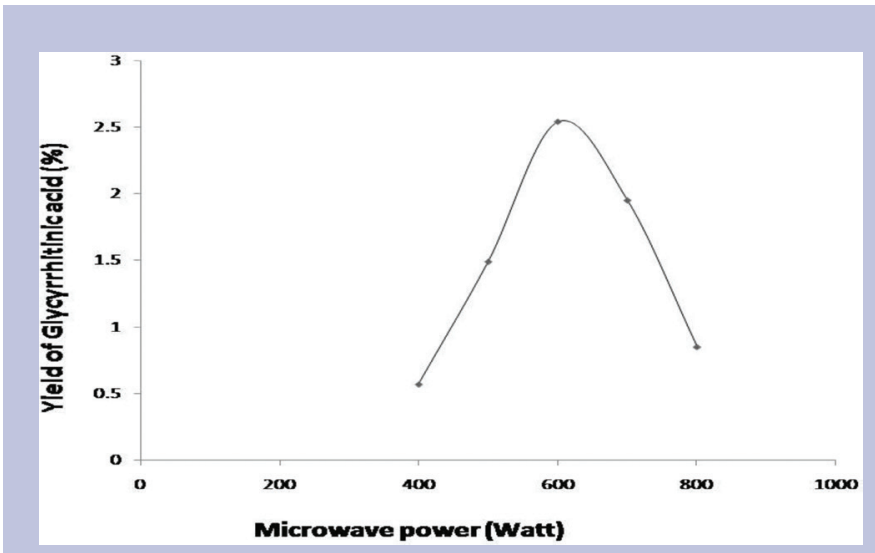

Figure 2: Impact of microwave power on the yield of glycyrrhitinic acid.

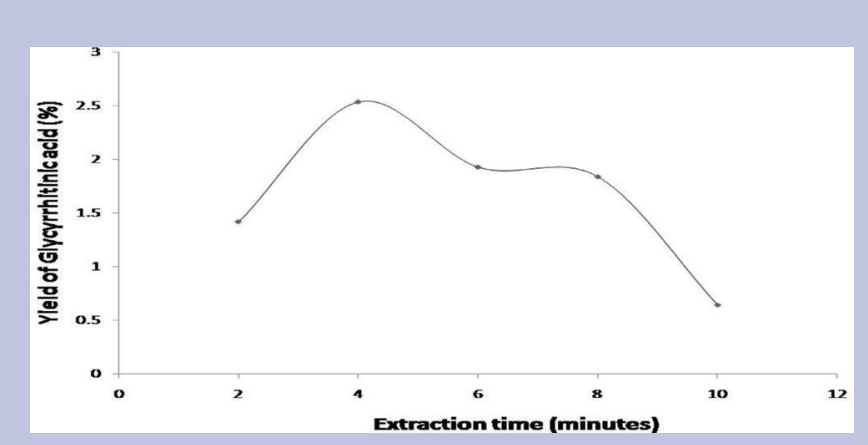

Figure 3: Impact of extraction time on the yield of glycyrrhitinic acid. concentration was increased to $4 \mathrm{~mol} / \mathrm{L}$, yield was decreased as shown in Figure 1. So, 1.0-3.0 mol/L was considered as the relevant concentration range for extraction.

\section{Impact of microwave power on the yield of glycyrrhitinic} acid

To know the impact of microwave power on the yield of glycyrrhitinic acid, extraction was carried out using $1.0 \mathrm{~g}$ sample with different microwave power of $400,500,600,700,800 \mathrm{~W}$ while other extraction parameters were: $[\mathrm{bmim}] \mathrm{Cl}$ concentrations $2.0 \mathrm{~mol} / \mathrm{L}$, extraction temperature $70^{\circ} \mathrm{C}$, extraction time $6 \mathrm{~min}$ and solid-liquid ratio 1:10. When the microwave irradiation power was $600 \mathrm{~W}$, the extraction yield of glycyrrhitinic acid was higher comparable to other power and starts decreasing at above 700 $\mathrm{W}$ as shown in Figure 2. So, 500- $700 \mathrm{~W}$ was selected as the microwave power range for the experimental design.

\section{Impact of extraction time on the yield of glycyrrhitinic} acid

To know the optimum extraction time for glycyrrhitinic acid, the extraction was carried out using $1.0 \mathrm{~g}$ sample, different extraction time from 2 to $10 \mathrm{~min}$, while other extraction parameters were: [bmim] Cl concentrations $2.0 \mathrm{~mol} / \mathrm{L}$ extraction temperature $70^{\circ} \mathrm{C}$, microwave power $600 \mathrm{~W}$ and solid-liquid ratio 1:10. The effect of different time on the yield of glycyrrhitinic acid was shown in Figure 3. The yield of glycyrrhitinic acid was increased gradually from 2 to $4 \mathrm{~min}$ and decreased after $6 \mathrm{~min}$. So, 2-6 min was selected as the extraction time for the experimental design.

\section{Impact of extraction temperature on the yield of glycyrrhitinic acid}

To know the impact of extraction temperature on the yield of glycyrrhitinic acid, extraction was carried out using $1.0 \mathrm{~g}$ sample, different extraction temperature of $40,50,60,70,80$ and $90^{\circ} \mathrm{C}$, while other extraction parameters were: $[\mathrm{bmim}] \mathrm{Cl}$ concentrations $2.0 \mathrm{~mol} / \mathrm{L}$, extraction time 6 min, microwave power $600 \mathrm{~W}$ and solid-liquid ratio 1:10. The max. conc. of glycyrrhitinic acid was observed when the temperature was at $70^{\circ} \mathrm{C}$, shown in Figure 4. When the extraction temperature was increased from $70^{\circ} \mathrm{C}$, the concentration of glycyrrhitinic acid was decreased sharply. So, $70^{\circ} \mathrm{C}$ was selected as the optimum temperature for the experimental design.

\section{Impact of solid-liquid ratio on the yield of glycyrrhitinic acid}

To know the impact of solid-liquid ratio on the yield of glycyrrhitinic acid, different solid-liquid ratio of 1:5, 1:10, 1:15, 1:20, (g:ml) were used, while other extraction parameters were: [bmim] Cl concentrations $2.0 \mathrm{~mol} / \mathrm{L}$, extraction time $6 \mathrm{~min}$, microwave power $600 \mathrm{~W}$ and extraction temperature $70^{\circ} \mathrm{C}$. The yield of glycyrrhitinic acid was similar with 1:10, 1:15, 1:20, shown in Figure 5. So, 1:10 solid-liquid ratio was selected, to avoid the wastage of chemical and make the method economically efficient. 


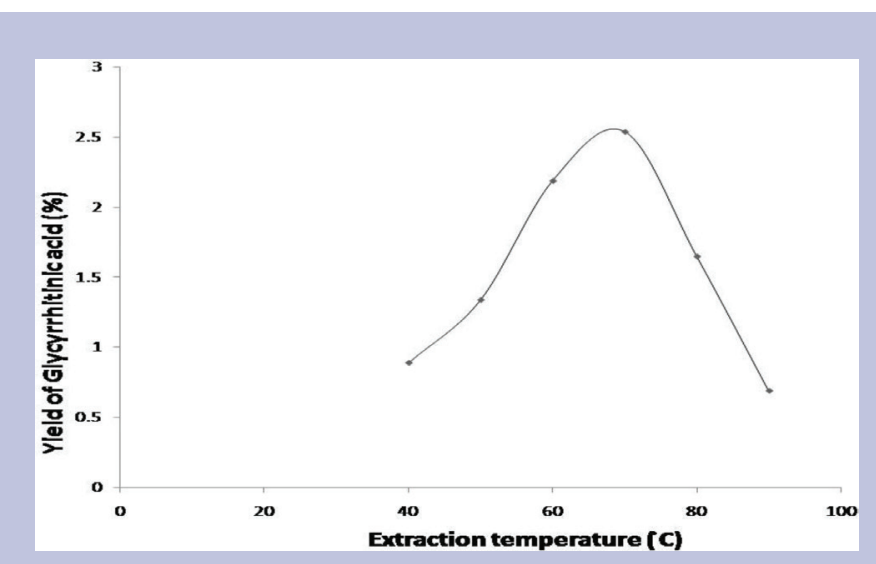

Figure 4: Impact of extraction temperature on the yield of glycyrrhitinic acid.

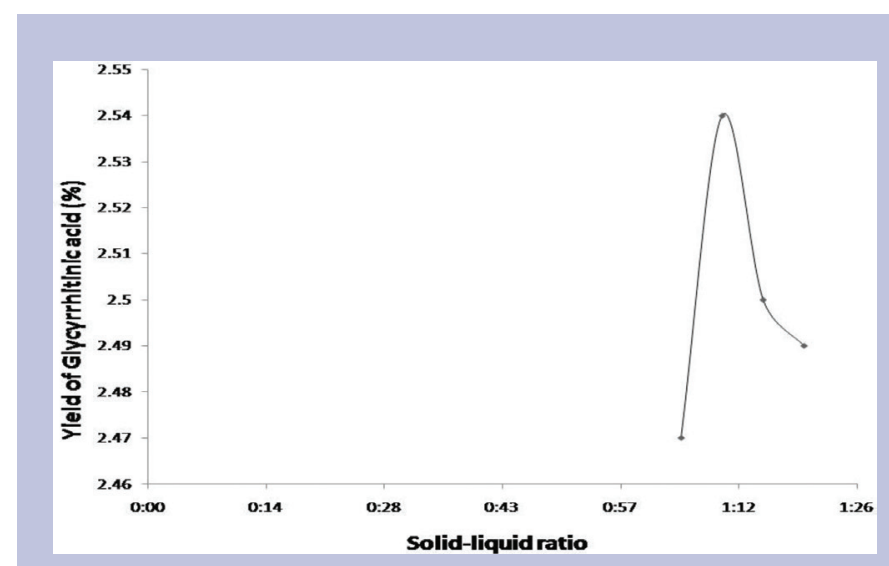

Figure 5: Impact of solid- liquid ratio on the yield of glycyrrhitinic acid.

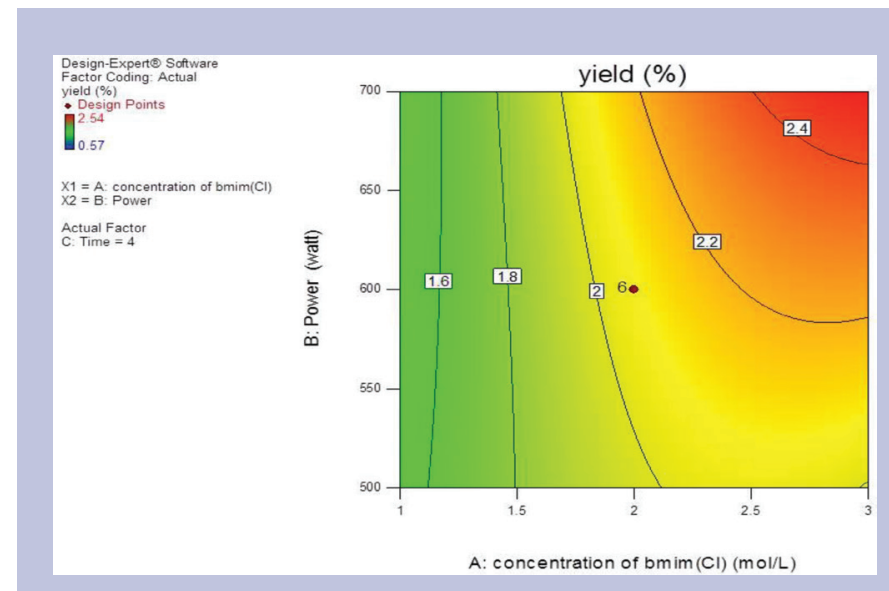

Figure 6: Contour plot.

\section{Conventional reference extraction methods}

The extraction yield of glycyrrhitinic acid from maceration and soxhlation was found to be $0.48 \% \mathrm{w} / \mathrm{w}$ and $0.76 \% \mathrm{w} / \mathrm{w}$ respectively.

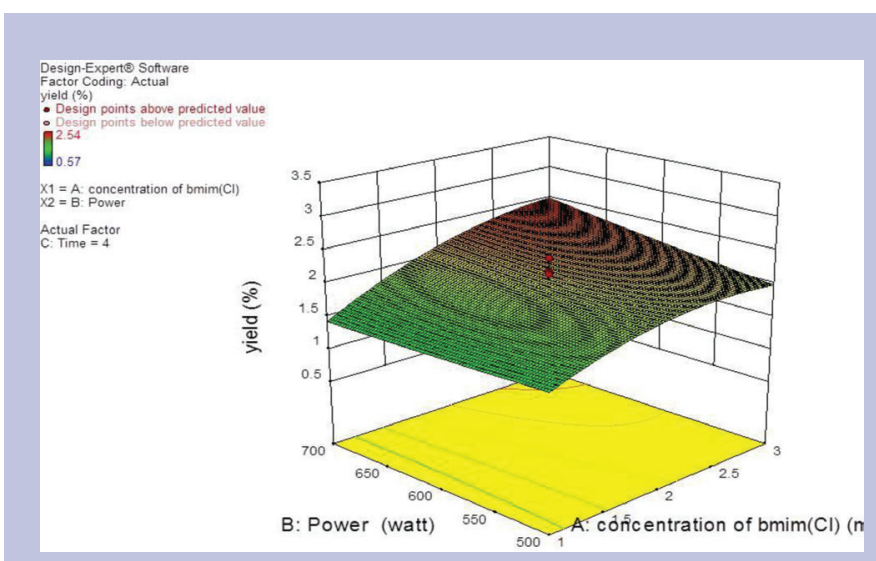

Figure 7: 3-D Response surface plot.

\section{RSM modelling and optimization of reactive extraction process}

The relationship between the response and the independent variables is determined by three-dimensional response surface plot. Lines of constant response drawn in the plane of the independent variables in two-dimensional display of the surface plot is called contour plot and it helps to visualize the shape of response surface. ${ }^{18}$

To know the impact of critical variables on the interested component yield, central composite design was utilized. To facilitate easy calculations and orthogonality of results, factor's real values were transformed. ${ }^{19}$ For each experiment there is a unique combination of factor levels, and for each the extraction efficiency Y (\%) was determined as shown in Table 2. The polynomial equation obtained was equation 1 :

$\mathrm{Y}=2.07+0.38 X 1+0.11 X 2+0.22 X 3+0.15 X 1 X 2+0.071 X 1 X 3-$ $0.096 X 2 X 3-0.22 X 12+0.012 X 22-0.36 X 32$ equation 1

Where $\mathrm{Y}$ represents the response i.e. yield of glycyrrhitinic acid and $\mathrm{X}_{1}$ $\mathrm{X}_{2}, \mathrm{X}_{3}$ are the variables concentration of $[\mathrm{bmim}] \mathrm{Cl}$, microwave power and extraction time respectively. The $\%$ yield was maximum at the high values of concentration of $[\mathrm{bmim}] \mathrm{Cl}\left(\mathrm{X}_{1}\right)$, mid values of microwave power $\left(\mathrm{X}_{2}\right)$ and extraction time $\left(\mathrm{X}_{3}\right)$. It was found to be the lowest at the mid value of $X_{1}, X_{2}$ and lowest value of $X_{3}$. The value of $X_{1}$ was found to be critically affecting the extraction efficiency. The square terms should be retained in the mathematical model to explain the curvature of response. Value of $F=3.87$, shows significant regression. Therefore, the predictive model, may be used as response surface for extraction efficiency.

Analysis of variance (ANOVA), F-test and p-value was performed for analysing the statistical significance of the response surface quadratic model as shown in Table 3.

Contour plot and $3 \mathrm{D}$ response surface plot were drawn to demonstrate the main and interactive effects of independent variables on the dependent variable as shown in Figures 6 and 7, respectively.

\section{Comparison of different extraction procedures}

To know the extraction efficiency of [bmim]Cl- microwave assisted extraction (IL-MAE), comparison was done between ILMAE, soxhlation and maceration. For comparison HPTLC was performed between standard glycyrrhitinic acid, ILMAE glycyrrhitinic acid, soxhlation glycyrrhitinic acid, maceration glycyrrhitinic acid. Figure 8 shows the comparasion through peak height and area by HPTLC chromatograms. From this peak area, yield was calculated. It was found to be $0.48 \% \mathrm{w} / \mathrm{w}$ in maceration, $0.76 \%$ in soxhlation and $2.54 \%$ in IL-MAE, which is $2.06 \%$ 


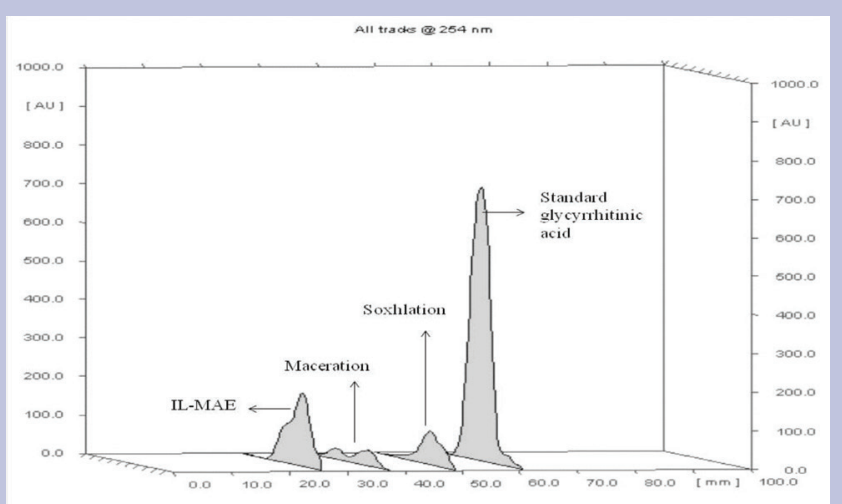

Figure 8: HPTLC chromatograms showing comparison between standard glycyrrhitinic acid, soxhlation, maceration and [bmim]CI (IL-MAE) extracted glycyrrhitinic acid.

higher in case of maceration and $1.78 \%$ higher in soxhlation. It clearly shows that ILMAE technique is much better than conventional methods of extraction in terms of extraction yield, extraction time and solvent consumption. All these greatly contribute to least energy consumption hence, much efficient extraction method.

\section{CONCLUSION}

A new optimized extraction method for IL-MAE was developed for the extraction of Glycyrrhiza glabra using response surface methodology. [bmim]Cl-microwave assisted extraction technique was proved to be better and efficient in respect of extraction efficiency, time, as well as quantity of solvent used.

So, the developed method can be used effectively as a mathematical model to estimate the extraction efficiency hence, can be used as an efficient extraction protocol at industrial level.

\section{ACKNOWLEDGEMENT}

I greatly acknowledge University Grant Commission, New Delhi for financial support and Department of Pharmaceutical Sciences, Maharshi Dayanand University, Rohtak, Haryana for providing instruments.

\section{CONFLICT OF INTEREST}

There is no conflict of interest.

\section{ABBREVIATION USED}

IL: Ionic liquid; ILs-MAE: Ionic liquid based microwave assisted extraction technique; [bmim]Cl: 1-butyl-3-methyl-imidazolium chloride; $\mu \mathrm{m}$ : Micrometer; Conc.: Concentration; mL: Milliliter; mol: Molar; $\mu \mathrm{g}$ : Microgram; g: Gram; nm: Nanometer; Min.: Minute; Max.: Maximum; UV: Ultraviolet; ANOVA: Analysis of variance; W: Watt; w/w: Weight by weight; CCD: Central Composite Design; RSM: Response surface methodology; HPTLC: High Performance Thin Layer Chromatography.

\section{REFERENCES}

1. Hamaguchi HO, Ozava R. Structure of ionic liquids and ionic liquid compounds: are ionic liquids genuine liquids in the conventional sense? Advances in Chemical Physics edited by Stuart A. Rice, Copyright John Wiley and sons. 2005:131:85-104.

2. Solanki HK, Prajapati VD, Jani GK. Microwave technology - a potential tool in pharmaceutical science. Int. J. Pharm. Tech. Res. 2010;2:1754-61.

3. Mora-Pale M, Meli L, Doherty TV, Linhardt RJ, Dordick JS. Room Temperature Ionic Liquids as Emerging Solvents for the Pretreatment of Lignocellulosic Biomass. Biotechn. Bioeng. 2011;108(6):1229-45.

4. Olivier-Bourbigou H, Magna L, Morvan D. Ionic liquids and catalysis: Recent progress from knowledge to applications. Appl. Catal. A: General. 2010;373(1):1-56.

5. Parvaiz M, Hussain K, Khalid S, Hussnain N, Iram N, Hussain Z, et al. A Review: Medicinal Importance of Glycyrrhiza glabra L. (Fabaceae Family) GJP. 2014; 8(1):8-13.

6. Sharma V, Agrawal RC. Glycyrrhiza glabra- A plant for the future. MJPMS 2013;2:15-20

7. Fenwick GR. Liquorice, Glycyrrhiza glabra L. Composition, uses and analysis. Food Chem. 1990;38(3):119-43.

8. Damle M. Glycyrrhiza glabra (Liquorice) - a potent medicinal herb. Int. J. Herb Med. 2014;2(2):132-6.

9. Gumpricht E, Dahl R, Devereaux MW, Sokol RJ. Licorice Compounds Glycyr rhizin and 18ß-Glycyrrhetinic Acid Are Potent Modulators of Bile Acid-induced Cytotoxicity in Rat Hepatocytes. J. Bio. Chem. 2005;280(11):10556-63.

10. Armaninia D, Nacamullia D, Francini-Pesentib F, Battagina G, Ragazzic E, Fiorea C Glycyrrhetinic acid, the active principle of licorice, can reduce the thickness of subcutaneous thigh fat through topical application. Steroids. 2005;70(8):538-42.

11. Nose M, Ito M, Kamimura K, Shimizu M, Ogihara Yukio. A Comparison of the Antihepatotoxic Activity between Glycyrrhizin and Glycyrrhetinic Acid. Planta Med. 1994;60(2):136-9.

12. Yang L, Li LL, Liu TT, Zu YG, Yang FJ, Zhao CJ, et al. Development of sample preparation method for isoliquiritigenin, liquiritin, and glycyrrhizic acid analysis in licorice by ionic liquids-ultrasound based extraction and high-performance liquid chromatography detection. Food Chem. 2013;138(1):173-9.

13. Li X, Guo R, Zhang X, Li X. Extraction of glabridin using imidazolium-based ionic liquids. Sep. Pur. Tech. 2012;88:146-50.

14. Doornbos DA. Optimisation in pharmaceutical sciences. Pharm. Weekbld $1981 ; 3(1): 549-77$.

15. Bas D, Boyaci IH. Modeling and optimization I: Usability of response surface methodology. J. Food Eng. 2007;78(3):836-45

16. Trivedi A, Mishra SH. A simple and rapid method for simultaneous estimation of glycyrrhetinic acid and piperine by HPTLC in a herbomineral formulation. J. Adv Pharm. Technol. Res. 2010;1(2):190-8.

17. Bhan M, Satija S, Garg C, Dureja H, Garg M. Optimization of ionic liquid-based microwave assisted extraction of a diterpenoid lactone-andrographolide from Andrographis paniculata by response surface methodology. Journal of Molecula Liquids. 2017:229:161-6.

18. Myers RH, Montgomery DC, Anderson-Cook CM. Response Surface Methodology: Process and Product Optimization Using Designed Experiments, 3rd edition, Hoboken, New Jersey. 2009.

19. Dureja H, Tiwary AK, Gupta S. Simulation of skin permeability in chitosan membranes. Int. J. Pharm. 2001;213(1):193-8.

\section{SUMMARY}

- IL-MAE of glycyrrhitinic acid from Glycyrrhiza glabra was performed and compared with conventional extraction procedures such as soxhlation and maceration. Microwave assisted extraction parameters such as concentration of ionic liquid [bmimCl], microwave power and extraction time played a major role in extraction The yield of glycyrrhitinic acid was found to be $0.48 \% \mathrm{w} / \mathrm{w}$ in maceration in 7 days, $0.76 \%$ in soxhlation in $3 \mathrm{~h}$ and $2.54 \%$ in IL-MAE in 4 min. It clearly shows that ILMAE technique is much better than conventional methods of extraction in terms of extraction yield, extraction time and solvent consumption. All these greatly contribute to least energy consumption hence, much efficient extraction method.

- The quadratic equation obtained was:

- $Y=2.07+0.38 X 1+0.11 X 2+0.22 X 3+0.15 X 1 X 2+0.071 X 1 X 3-0.096 \times 2 X 3-0.22 X 12+0.012 X 22-0.36 X 32$

- Where $\mathrm{Y}$ represents the response i.e. yield of glycyrrhitinic acid and $\mathrm{X} 1, \mathrm{X} 2, \mathrm{X} 3$ are the variables concentration of [bmim]Cl, microwave power and extraction time respectively. The \% yield was maximum at the high values of concentration of $[\mathrm{bmim}] \mathrm{Cl}(\mathrm{X} 1)$, mid values of microwave power $(\mathrm{X} 2)$ and extraction time $(\mathrm{X} 3)$. It was found to be the lowest at the mid value of $\mathrm{X} 1, \mathrm{X} 2$ and lowest value of $\mathrm{X} 3$. The value of $\mathrm{X} 1$ was found to be critically affecting the extraction efficiency. The square terms should be retained in the mathematical model to explain the curvature of response.

- Value of $F=3.87$, shows significant regression. Therefore, the predictive model, may be used as response surface for extraction efficiency.

- So, the developed methods can be used as efficient extraction protocols at industrial level. 


\section{GRAPHICAL ABSTRACT}

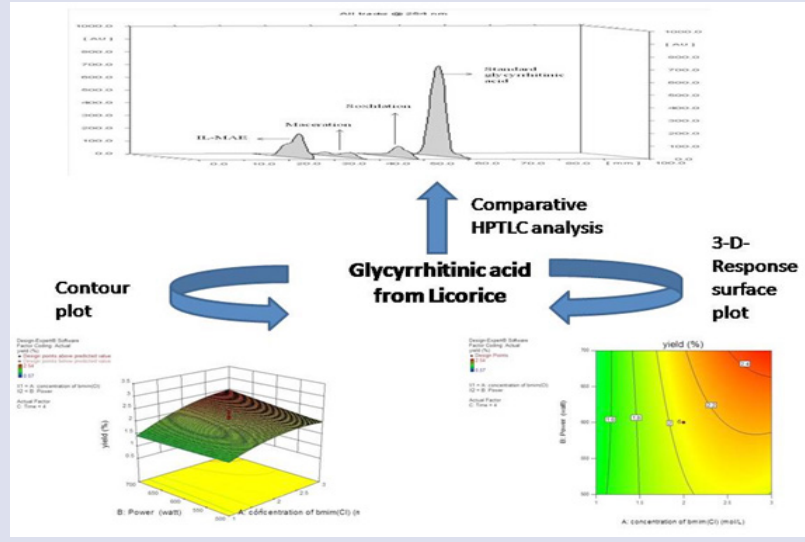

\section{ABOUT AUTHORS}

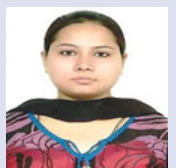

Meenu Bhan: Department of Pharmaceutical Sciences, Maharshi Dayanand University, Rohtak, Haryana, India.

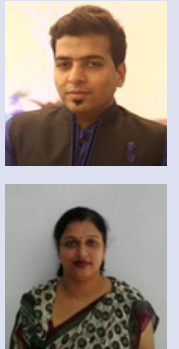

Saurabh Satija: Assistant Professor School of Pharmaceutical Sciences Lovely Professional University, Punjab, India.

Chanchal Garg: Department of Pharmaceutical Sciences, Maharshi Dayanand University, Rohtak, Haryana, India.

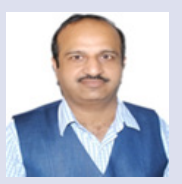

Harish Dureja: Department of Pharmaceutical Sciences, Maharshi Dayanand University, Rohtak, Haryana, India.

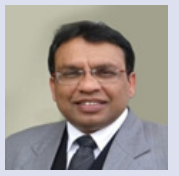

Munish Garg: Department of Pharmaceutical Sciences, Maharshi Dayanand University, Rohtak, Haryana, India.

Cite this article: Bhan M, Satija S, Garg C, Dureja H, Garg M. A Novel Approach towards Green Extraction for Glycyrrhitinic Acid by lonic Liquid Based Microwave Assisted Extraction and Optimization through Response Surface Methodology. Pharmacog J. $2017 ; 9(6): 866-72$. 